\title{
A Water Body Extraction Methods Comparison Based on FengYun Satellite Data: A Case Study of Poyang Lake Region, China
}

\author{
Xufeng Wei ${ }^{1}$, Wenbo $\mathrm{Xu}^{1, *}$, Kuanle Bao ${ }^{1}$, Weimin $\mathrm{Hou}^{2}$, Jia Su ${ }^{2}$, Haining $\mathrm{Li}^{2}$ and \\ Zhuang Miao ${ }^{2}$ \\ 1 School of Resources and Environment, University of Electronic Science and Technology of China, \\ Chengdu 610054, China; weixufeng@uestc.edu.cn (X.W.); 201821070223@std.uestc.edu.cn (K.B.) \\ 2 School of Information Science and Engineering, Hebei University of Science and Technology, \\ Shijiazhuang 050018, China; hwm@hebust.edu.cn (W.H.); sujia@hebust.edu.cn (J.S.); \\ lihaining@stu.hebust.edu.cn (H.L.); miaozhuang@stu.hebust.edu.cn (Z.M.) \\ * Correspondence: xuwenbo@uestc.edu.cn; Tel.: +86-138-8060-5460
}

Received: 26 October 2020; Accepted: 24 November 2020; Published: 26 November 2020

\begin{abstract}
Water body extraction can help eco-environmental policymakers to intuitively grasp surface water resources. Remote sensing technology can accurately and quickly extract surface water information, which is of great significance for monitoring surface water changes. Fengyun satellite images have the advantages of high time resolution and multispectral bands. This provides important image data suitable for high-frequency surface water monitoring. Based on Fengyun 3 medium resolution spectral imager (FY-3/MERSI) data, 7 methods were applied in this study, which include single-band threshold method, water body index method, knowledge decision tree classification method, supervised classification method, unsupervised classification method, spectral matching based on discrete particle swarm optimization (SMDPSO), and improved spectral matching based on discrete particle swarm optimization with linear feature enhancement (SMDPSO+LFE). These methods were used to extract the land surface water of Poyang Lake, check the samples from the Landsat image with similar times to the FY-3 images, and calculate the classification accuracy via the confusion matrix. The results showed that the overall classification accuracy $(\mathrm{OA})$ of the SMDPSO+LFE is $97.64 \%$, and the Kappa coefficient is 0.95 . To analyze the stability of the surface water extracted by SMDPSO+LFE in different regions, this paper selected eight test sites with different surface water types, landscapes, and terrains to extract surface water. Based on an analysis of the land surface water results at the eight test sites, every OA in the eight sites was higher than $94.5 \%$, the Kappa coefficient was greater than 0.88. In conclusion, the SMDPSO+LFE is found to be the most suitable method among the 7 methods and effectively distinguish between different surface water bodies and backgrounds with good stability.
\end{abstract}

Keywords: water body extraction; remote sensing; FY-3/MERSI; SMDPSO+LFE method

\section{Introduction}

Water body extraction plays a significant role in ecological environment monitoring, the information it provides can help in the utilization and protection of water resources, the evaluation and prevention of natural disasters such as floods, and the guidance of agricultural production around the waters [1]. Since the beginning of remote sensing more than 40 years ago, this technology has become increasingly mature, helping us quickly and comprehensively obtain the distribution of surface water and continuously monitor its dynamic changes. Remote sensing technology has advantages over conventional surface water mapping methods because it is low-cost, source-reliable, has high 
conducting frequency, and makes repeatable observations. Many studies [2-5] have successfully used surface water extraction based on remote sensing images and multi-source remote sensing data such as moderate resolution imaging spectroradiometer (MODIS), small satellite constellation (HJ-1 a/B), multispectral scanner system (MSS), thematic mapper (TM), and enhanced thematic plotter (ETM +) to extract data on epicontinental water bodies. In particular, MODIS images have the advantages of 36 band range channels and a short return cycle, so they are widely used not only for the detection of land surface water but also for the inversion detection of global surface types and vegetation indicators [2-5].

With technological development, researchers continue to explore more advanced methods for water body extraction by using remote sensing technology. Improving the accuracy of information extraction and imaging has become the focus of research. In 2018, Wang and Qin pointed out that the combination of remote sensing spectroscopy with the physical and chemical properties of water is an important method currently studied to improve the accuracy of water extraction [4]. Jiang et al. used a multilayer perceptron (MLP) neural network for surface water accurate identification [6]; 2019, Hong et al. claimed that automatic sub-pixel coastline extraction method (ASPCE) can accurately distinguish land and water area [7]; 2017, Yang and Du used principal component analysis (PCA) and modified normalized difference water index (MNDWI) to improve the accuracy of water extraction [8]; Normalized difference water index (NDWI) and Sentinel-2 Water Index (SWI) method were used by Jiang et al. at 2020 to reach higher spatial and spectral resolution [9].

The MERSI data of FY-3 is very similar to MODIS data. FY-3/MERIS enhances the ability to observe fine surface features. Based on the MODIS spatial resolution of $250 \mathrm{~m}$ data, MERSI data add 3 bands to the resolution of this data, especially the thermal infrared data at 10.5-12.5 $\mu \mathrm{m}$ in the first channel, which enables FY-3/MERSI images to detect the $250 \mathrm{~m}$ spatial resolution of some natural disasters such as typhoons, debris flow, and landslide. There are few studies on using FY-3/MERSI to extract surface waters, and the application of FY-3/MERSI data still has significant room for exploration. The parameters comparison between FY-3/MERIS and MODIS is shown in Table 1.

Table 1. Parameters of moderate resolution imaging spectroradiometer (MODIS) and Fengyun 3 medium resolution spectral imager (FY-3/MERSI).

\begin{tabular}{ccccc}
\hline & \multicolumn{2}{c}{ MODIS } & \multicolumn{2}{c}{ FY-3/MERSI } \\
\hline & Band Range (nm) & Spatial Resolution (m) & Band Range (nm) & Spatial Resolution (m) \\
\hline 1 & $620-670$ & 250 & $445-495$ & 250 \\
2 & $841-876$ & 250 & $525-575$ & 250 \\
3 & $459-479$ & 500 & $625-675$ & 250 \\
4 & $545-565$ & 500 & $840-890$ & 250 \\
5 & $1230-1250$ & 500 & $10,000-12,500$ & 250 \\
6 & $1628-1652$ & 500 & $402-422$ & 1000 \\
7 & $2105-2155$ & 500 & $433-453$ & $400-12,500$ \\
\hline Spectrum range $(\mathrm{nm})$ & $400-14,400$ & \multicolumn{3}{c}{20} \\
\hline Number of bands & 26 & & $0.25-1$ \\
\hline
\end{tabular}

In the water body extraction method, since the 1970s, increasingly more scholars have engaged in the exploration and analysis of the remote sensing applications of surface waters. The methods for classifying surface waters based on visible remote sensing data include the single-band threshold method, the multi-band method, the conventional land classification method, and the special water extraction method. Among the commonly used methods for extracting land surface water, the single-band threshold method and the multi-band method are simple to calculate and convenient to construct, but they have many topographic restrictions. For images in different regions and at different times, the threshold settings are different, and these two methods' adaptabilities are relatively poor [10-15]. Conventional land classification methods, such as supervised classification, unsupervised classification, and the decision tree method, have a large workload in the process of building a 
relevant model. At the same time, it is necessary to adjust the conditions in the classification of images for different times and regions. Moreover, their adaptabilities are relatively poor. Surface water extraction methods make full use of the spectral characteristics of land surface water bodies. At present, the particle swarm optimization (PSO) technique is a new kind of evolutionary algorithm based on the observations of bird groups looking for food [16]. Currently, discrete particle swarm optimization (DPSO) has been fully used to extract land surface information from remote sensing images, in order to improve the integrity of the algorithm for water body extraction. PSO has intelligent characteristics of self-adaptation and self-organization, as well as the advantages of simple calculation, fast convergence, and strong stability [17-19]. Thus, as an intelligent optimization algorithm, PSO has a very strong ability to determine an optimal solution, which has been increasingly more introduced for the special classification of surface waters in remote sensing images.

By combining the characteristics of DPSO with spectral information, Jia et al. made full use of water information with fewer parameters to complete the classification process for land surface water and published the SMDPSO [20]. With the advantages of low parameter demand and strong portability, this method can be easily combined with more surface water features.

Fengyun satellite data has good timeliness, which can help us to evaluate the flood invasion area in time and provide necessary guidance for disaster relief. Yu et al. used the image and spectral characteristics of FY 3 MERSI data from 1 to 5 bands, analyzed the performance characteristics of vegetation, towns, soil, and water on MERSI images, and performed various water recognition models. A water body index expansion model suitable for MERSI data has been put forward by them. Due to the limitations of obtaining the permission of satellite data acquisition, there are relatively few studies on water extraction methods using Fengyun satellite data [21].

This paper primarily uses FY-3/MERSI images to extract surface water from Poyang Lake. The classification of land surface waters is mainly completed by using the single-band threshold, water index, decision tree classification, supervised classification, unsupervised classification, SMDPSO and SMDPSO+LFE algorithms. After comparing the coefficients of OA, Kappa, f1, and miou of the various models and methods, the best method for the classification of land surface waters is selected. Moreover, the stability and sensitivity analyses are completed using this method.

Selecting an accurate, sensitive, and stable method is essential for water body information extraction in the Poyang Lake region. However, seven potential water extraction methods are known, but it is not clear which one is the most acceptable. The following study will determine the most appropriate method for water extraction in Poyang Lake. The research area and data section will explain the selection of the water body information of the Poyang Lake, and the spectroscopic characteristics of FY-3 data the Landsat 8 operational land imager (OLI) data. The source of these data will be explained at the same time. The methodology part includes the pre-processing of FY-3 and Landsat 8 OLI images, and the algorithms of 5 traditional methods, SMDPSO method, and SMDPSO+LFE method. Methods of validation and accuracy evaluation will also be provided. Then, the results section will give the accuracy comparison of the 7 methods and the sensitivity and stability test results of the most accurate method. The advantages and disadvantages of the 7 methods will be discussed in the discussion section. The conclusion of this research will be provided at the end.

\section{Study Area and Data}

\subsection{Study Area}

Poyang Lake is the largest freshwater lake in China and is also an alternately inflow-outflow lake with seasonal variations. The lake's surface area can reach more than $4000 \mathrm{~km}^{2}$ during the flood season. The elevation of the Poyang Lake area gradually decreases from east to west and south to north. From June to September every year is the wet season in the Poyang Lake region. The water level of the lake rises rapidly due to the sudden increase in the runoff of the five inflow rivers. In fall, with the continuous strengthening of the cold air current, the rainfall in the Poyang Lake region is continuously decreasing, which leads to the 
dry season in the Poyang Lake region. The dry season lasts from October to March of the following year. There are obvious differences in the water level, surface area, and water quality between the wet season and the dry season [22]. The map of Poyang Lake region is shown in Figure 1.

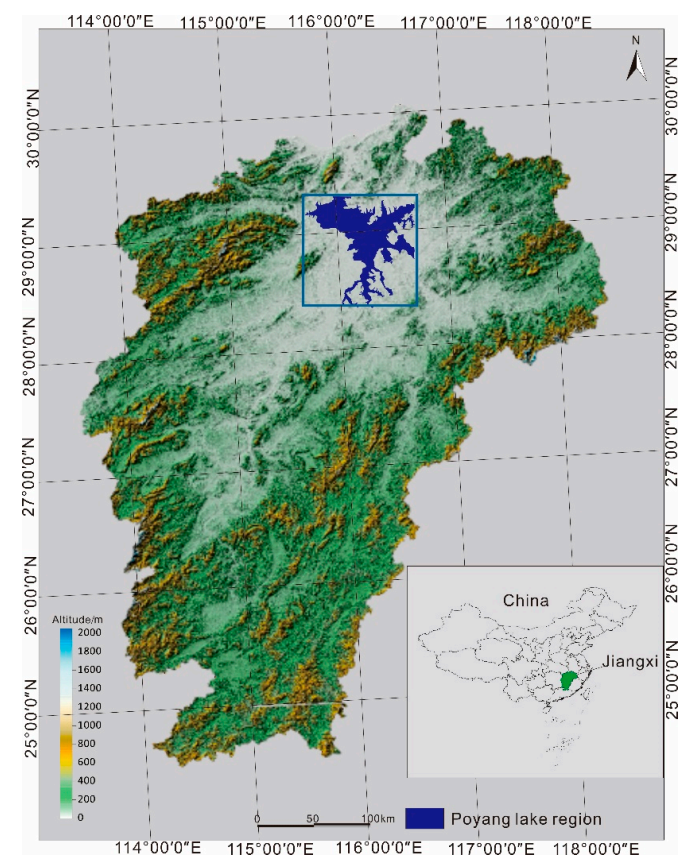

Figure 1. Map of the Poyang Lake, Jiangxi Province, China.

At the same time, the vegetation growth distribution of Poyang Lake is also significantly affected by the differences in terrain, the lake's surface area, and the water level in flood and drought periods. From March to the middle of May, when Poyang Lake's water level is relatively low, five small rivers flow into the lake, making the wetland vegetation grow rapidly. However, with an increase in the water level, wetland vegetation is submerged by lake water. After fall, the water level gradually reduces, and the land area becomes occupied by wetland vegetation again until the plants' wither period [23]. Affected by the topographic characteristics of the south (high) and the north (low) at the bottom of Poyang Lake and the rapid increase in the runoff of five rivers in the summer flood season, the surface area and water level of Poyang Lake vary greatly with the changes of seasons, showing many special phenomena, such as obvious seasonality and variability [10,11]. The study area in this research is mainly the surface water in the southern part of Poyang Lake, small tributaries, and shallows of the southern bank [12].

\subsection{Data}

This study uses FY-3 data to test these 7 methods. The FY-3 satellite has an orbital altitude of 836 kilometers, an inclination of 98.75 degrees, and an orbit time of 102 minutes around the earth. FY-3 is loaded with up to 11 sensor types, including a visible infrared scanning radiometer (VIRR) and a medium resolution spectral imager (MERSI). MERSI on FY-3 can detect cloud and surface features with a width of $2000 \mathrm{~km}$ and a resolution of $250 \mathrm{~m}$. The spectrum ranges from 0.41 to $12.5 \mu \mathrm{m}$, and the ground resolution is 250 to $1000 \mathrm{~m}$. In this paper, images of the first four bands in the FY-3/MERSI daily images were selected for surface water extraction. The spatial resolution is $250 \mathrm{~m}$, including the blue, green, red, and near-infrared bands.

\subsection{Validation}

This research uses the Landsat 8 OLI data as a reference to validate the 7 methods. The verification data, 2016 Landsat 8 OLI data, were downloaded from the geospatial data cloud 
website (http://www.gscloud.cn/) with a resolution of $30 \mathrm{~m}$. In this study, Landsat 8 OLI image data from 17 September 2016, were used due to having less cloud cover and clear images. These image data effectively reflect the distribution of land surface water. Moreover, the corresponding verification samples were checked against the Landsat 8 OLI data, and scale transformation and integration were carried out, thereby providing the reference images for the accuracy analysis of the experimental results. Verification samples corresponding to the eight stability test areas were checked using the Google Earth data, which served as reference images for the accuracy analysis of the experimental results.

Since Poyang Lake is a seasonal lake [10], the difference between its dry season and the wet season is conspicuous. Therefore, we used Landsat 8 OLI data from 17 September 2016, which is in between the two different seasons, as the reference data and selected the corresponding verification samples. The confusion matrix was calculated from the results of the classification method used in this paper, and the coefficients of OA, Kappa, f1, and miou were obtained to evaluate the classification method [24-27].

The stability of the surface water extraction method was mainly limited by the high spectral and spatial diversity of the water bodies and the inhomogeneity of adjacent surfaces in different regions. Therefore, eight test sites characterized by different surface water types, landscapes, and terrains were selected to evaluate the stability of the surface water extraction methods.

These water bodies at these different locations consist of many small lakes, linear or irregular rivers, artificial reservoirs, and lakes composed of waterways in coastal areas.

Given that the features of these heterogeneous landscapes are spatially variable, the test areas were selected from coastal areas to inland areas, which are characterized by diverse climatic conditions, such as deserts, rain forests, deltas, and tropics.

Specifically, (i) sites located in harbors are characterized by a complex composition of seawater and constructed lakes. The mixture of an urban surface appearance and building shadows at these sites creates considerable obstruct for the accurate extraction of target waters; (ii) the waters of natural coasts and bays consist mainly of small reservoirs and tidal creeks, making them ideal sites for study. Suspended matters and abundant hydrophyte are covered in such areas, making it very difficult to map waters; (iii) due to the abundance of water resources (dense river networks and alpine lakes), locations in tropical rain forests and subtropical monsoon climates are also considered; (iv) as the distance between the land increases, the middle and high latitudes become prone to misclassifications related to mountain shadows or snow cover. All eight test sites are briefly summarized in Table 2.

Table 2. Test point characteristics and their latitude and longitude.

\begin{tabular}{cccc}
\hline & Country & Characteristics/Source & Latitude and Longitude \\
\hline A & $\begin{array}{c}\text { Thailand/ } \\
\text { Asia mountain }\end{array}$ & lakes, shallow rivers/mountains of shadow and aquatic plants & $14^{\circ} \mathrm{N}, 98^{\circ} \mathrm{E}$ \\
\hline B & $\begin{array}{c}\text { Lake Gandhi/ } \\
\text { India/Asia }\end{array}$ & Common grassland lakes, shallow rivers/silt, mudflats & $24^{\circ} \mathrm{N}, 75^{\circ} \mathrm{E}$ \\
\hline C & $\begin{array}{c}\text { Aral Sea/ } \\
\text { Kazakhstan/ Asia }\end{array}$ & Salt lake, high salt/silt, mudflat & $45^{\circ} \mathrm{N}, 58^{\circ} \mathrm{E}$ \\
\hline D & $\begin{array}{c}\text { Nasser reservoir/ } \\
\text { Egypt/Africa }\end{array}$ & The dark side of the man-made reservoir/mountain & $22^{\circ} \mathrm{N}, 32^{\circ} \mathrm{E}$ \\
\hline E & $\begin{array}{c}\text { Congo river/ } \\
\text { Congo/Africa }\end{array}$ & High FVC, multiple rivers/phytoplankton & $1^{\circ} \mathrm{S}, 17^{\circ} \mathrm{E}$ \\
\hline F & $\begin{array}{c}\text { Magdalena river/ } \\
\text { Colombia/ } \\
\text { South America }\end{array}$ & High sand content, lakes/coastal plants, tidal, silt & $10^{\circ} \mathrm{N}, 74^{\circ} \mathrm{W}$ \\
\hline G & Mexico/North America & Estuarine lake/sea plant effects, tidal streams, mud & $18^{\circ} \mathrm{N}, 92^{\circ} \mathrm{W}$ \\
\hline
\end{tabular}




\section{Methodology}

\subsection{Pre-Process}

A method that can be used to improve the geometric errors of the FY-3/MERSI image was adopted. According to the image characteristics of the FY-3/MERSI image, four corresponding error categories (90\% control point error (CE90), plane geometric error (RMSEH), meridional geometric error (RMSEX), and zonal geometric error (RMSEY)) were determined to calculate the geometric error of the FY-3/MERSI image. Firstly, the image registration in the FY-3/MERSI research area was confirmed via the specific registration points and geometric error analysis, and then the geometric error correction was carried out for the other time-series images in the research area. Lastly, the radiometric calibration was completed.

The research area of Poyang Lake in this paper is relatively small, so the regional shape of the research area was cut out from the FY-3/MERSI image. Meanwhile, the Landsat8 OLI image for accuracy verification is obtained from the same area $[10,12,28]$. In the stability analysis of the surface water extracted by the relatively most accurate water extraction method, the corresponding study area images were also selected from the FY-3/MERSI images.

The data in this paper used remote sensing image automatic matching technology to perform control point matching processing on the FY-3/MERSI satellite remote sensing data that has been systematically geometrically corrected. Then FY-3/MERSI data were used to determine its geometric positioning error according to the control point of the same name and perform detailed errors on a single image verification and analysis.

In this study, Level 1a data, which is unprocessed instrument data with geo-referenced and time-referenced parameters [29], was applied, and the geometric correction was performed based on the latitude and longitude data it provides. The geometric correction in this process is a systematic geometric correction. Then the data was mosaicked and trimmed according to the spatial scope of the study area to generate data of spatial extent covered the study area.

In this pre-processing, Proba-V100m image data is selected as the reference image for analyzing the positioning accuracy of FY-MERSI image data. Using computer artificial intelligence processing methods, automatically find the same control points of the reference image and the image to be processed, the most important of which is the corner detection operator. There are many types of image matching operators; image matching based on image features is the most common operator. Among the image matching operators based on point features, the Moravec corner detection algorithm is one of the earliest corner detection algorithms. The algorithm detects each pixel of the image, treats a certain window around the pixel as a block, and detects the correlation between this block and other surrounding blocks. This correlation is measured by the sum of the squared differences between two blocks. The smaller the value, the higher the similarity. The image matching in this paper is realized under the support of ENVI. The ENVI software provides Moravec and Forster operators to find the same control points. In this process, the Moravec operator is selected and the correlation coefficient is set to 0.95 to determine the effective control points [30].

\subsection{Conventional Process}

\subsubsection{Extraction of Surface Water by Single-Band Threshold Method}

According to the reflectance characteristics of the FY-3/MERSI image for different ground object types, the most prominent band was selected for threshold segmentation and land surface water extraction. Taking FY-3/MERSI data as an example, the reflectance values of land surface water, vegetation, and soil vary greatly with the wavelength changes. Land surface water basically absorbs all the spectral values of sunlight in the near-infrared band, and only a very small part of it is reflected, while vegetation and soil have the opposite trend to land surface water. This leads to the soil, building, vegetation, and surface water bodies showing huge differences in imaging. In this experiment, 
the threshold value was set for the FY-3/MERSI Band 4. In the early stages of establishing the model, to analyze the reflectance of these classified samples in the near-infrared band, samples of the edge of land surface water, small tributary watershed, vegetation, bare land, soil, etc., were selected for study. The water and other surface epicontinental types showed two obvious peaks in the histogram: pure land surface water and vegetation. Sandwiched between these two peaks is an epicontinental fuzzy area of the water body and bare land construction. The gray value corresponding to the position of the trough is selected as the threshold interval of the single-band threshold method. After repeated tests, the threshold value was determined to be 0.1516 .

\subsubsection{Extraction of Surface Water by Water Index Method}

In remote sensing, NDVI $=(\mathrm{NIR}-\mathrm{R}) /(\mathrm{NIR}+\mathrm{R})$, where NIR is the reflection value of the near-infrared band, and $R$ is the reflection value of the red band [13,31]. NDWI $=(G-N I R) /(G+N I R)$, where NIR is the reflection value of the near-infrared band, and $G$ is the reflection value of the green band $[14,15]$. In this experiment, NDWI was used to classify the surface water of Poyang Lake. FY-3/MERSI green light and near-infrared band were used to establish ratio relationship, and the characteristics of terrestrial surface water were emphasized from the image. The threshold value of the water index method is 0 to complete the classification and extraction of surface water.

\subsubsection{Extraction of Surface Water by Knowledge Decision Tree Classification Method}

The four-channel data of the FY-3/MERSI image were selected to calculate the values of the NDVI; NDWI; and the sum of the reflectance values of green light, red light, and the near-infrared band according to their formulas. The slope value was calculated using elevation data [32-34]. The above data is used as the basis for decision tree nodes. The knowledge decision tree is shown in Figure 2, where NDVI represents the normalized vegetation index, NDWI represents the normalized water index, and Sum_grn represents the sum of the reflectance values of the green light, red light, and near-infrared bands [35]. Using the prior knowledge, the image bands are analyzed according to the samples and then the decision tree is generated [36,37].

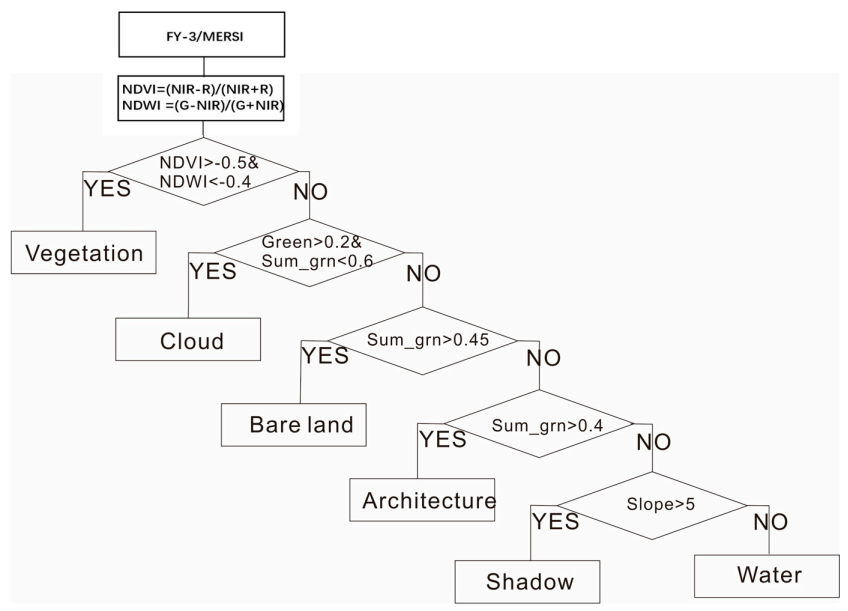

Figure 2. Knowledge decision tree classification diagram.

\subsubsection{Extraction of Surface Water by Supervised Classification Method}

Supervised classification is mainly separate into three steps. The first is to define the category. In this experiment, FY-3/MERSI images are characterized by visual interpretation. According to FY-3/MERSI image features, surface features are divided into four categories: surface water, bare land, architecture, and vegetation. The second is for sample selection, which in turn evenly sample selection on the remote sensing image classification and then calculate all separability between samples. Sample can be separating degree value between 0 and 2, if the separated degrees of the sample were greater 
than 1.9 , the next classification step will be started. Otherwise, the program will modify the input data or check the classified samples again. The third is classifier selection. This study selects the support vector machine (SVM) method in supervised classification. SVM can construct a variety of vectors according to the characteristics of image data channels and select the support vector with better performance for classification, to maximize the class spacing of all surface types and establish supervisory classification rules based on this. Landsat verification data also adopts the supervision classification method of the above steps. The data collection of supervised classification method is to select water and non-water areas in the study area by visual discrimination, using the digital number (DN) value of each band as the input data. The water data is selected for study as the target data, training it through a supervised training model such as SVM, applying it to the entire region after obtaining the model data.

\subsubsection{Extraction of Surface Water by Unsupervised Classification Method}

The main parts of unsupervised classification are the following three steps. The first step is image analysis. The number of classifications is determined based on the remote sensing image characteristics. In this paper, based on the image characteristics of the Poyang Lake study area, the image classification categories are defined as vegetation, bare land, buildings, and water bodies. When selecting the number of classifications, the number is roughly 2-3 times the number of land surface classifications, and finally the number of classifications in unsupervised classification is set to 12. The second step is classifier selection. The corresponding unsupervised classifier is selected according to the spectral characteristics of the remote sensing image data, the number of classifications, and the selection rule of the sample. In this paper, the K-Means method is applied, which determines the center of different categories based on the similarity of different pixels in the remote sensing image position and then iteratively calculates the distance between all the pixels to be classified and the center positions of different categories to select the most similar feature type for aggregation. The third step is category definition and consolidation. According to the linear representation of the categories of FY-3/MERSI images, the categories of the unsupervised classification results are determined and merged with the same categories.

\subsection{Extraction of Surface Water by the SMDPSO Method}

The SMDPSO method extracts water bodies in two main steps. First, the water probability image is obtained from the multispectral data by the proposed spectral matching method. Then, the water pixels are identified from the water probability image by using the DPSO method [20]. The purpose of surface water bodies extraction based on FY-3/MERSI images is to solve the problem of pixels or discrete image pixels. However, the basic particle swarm optimization (PSO) is mainly used to solve the problem of continuous space, but it cannot solve the problem of discrete space. Therefore, we applied discrete binary PSO $[37,38]$. By selecting standard spectra from the FY-3/MERSI image to calculate the water probability, the water probability image was divided into $4 \times 4$ blocks. For each different block, a spectral matching algorithm based on discrete particle swarm optimization was used to extract the land surface water $[18,19]$. The flow chart is shown in Figure 3.

Because NDWI makes full use of the regularity of surface water reflection spectral curves, it has a good response to water bodies. Thus, the value of the NDWI is introduced into the calculation of water probability. The water probability image of the study area obtained by calculations is shown in Figure 4.

To make the DPSO algorithm more sensitive to various surface types in the process of extracting land surface water, the image is roughly classified based on the mean value $\mu$ and standard deviation $\sigma$ of the pixel water probability. The judgment conditions and flow charts of the four coarse classifications are shown in Figure 5. 


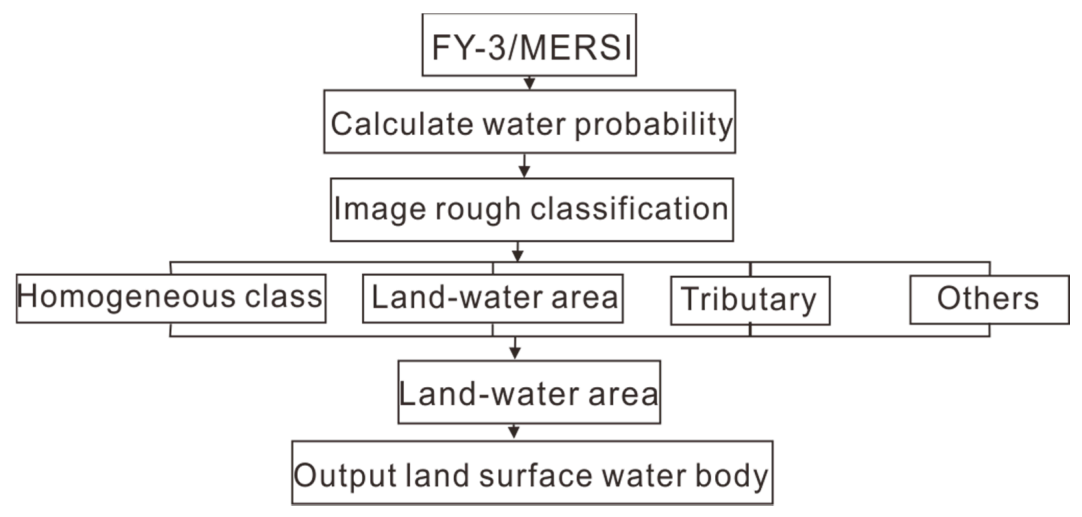

Figure 3. The flow chart of spectral matching based on discrete particle swarm optimization (SMDPSO).

The high $\mu / \sigma$ value of rough classification 1 indicates that the block has a high probability of water homogeneity or a low standard deviation, and the pixel feature of the block is likely to be a homogeneous land surface water body or a homogeneous non-water surface. The comparatively lower $\mu / \sigma$ values of rough classifications 2,3 , and 4 indicate that the block has a lower water probability mean value or a higher standard deviation, and the pixel features of the block are more likely to be mixed features. In the rough classification of a low $\mu / \sigma$ value, three categories were classified according to the size of the water probability value. Classification 2 has a highest water probability mean value, indicating that the pixel feature of this block is more likely to be the boundary between water and land and also more likely to be the boundary between small water and vast land areas. Classification 3 offers a medium water probability mean value, indicating that the block is more likely to have small tributaries and that more water probability information from other types is mixed in the block. Classification 4 provides the lowest water probability mean value and a relatively high-water probability standard deviation, indicating that it is more likely to be a mixed block of non-water land, such as the boundary between bare land and vegetation, and the boundary between buildings and vegetation. A rough classification diagram of the Poyang Lake research area is shown in Figure 6.

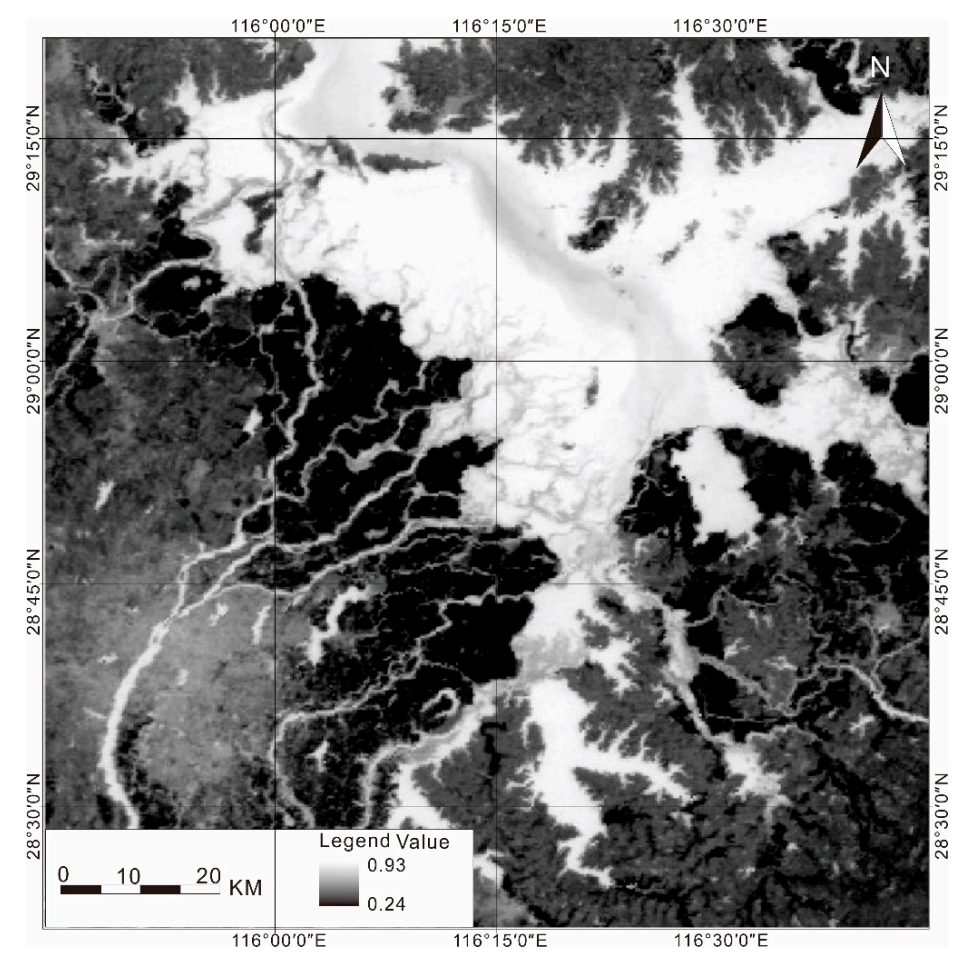

Figure 4. Water probability (normalized difference water index (NDWI)) map of the Poyang Lake area. 


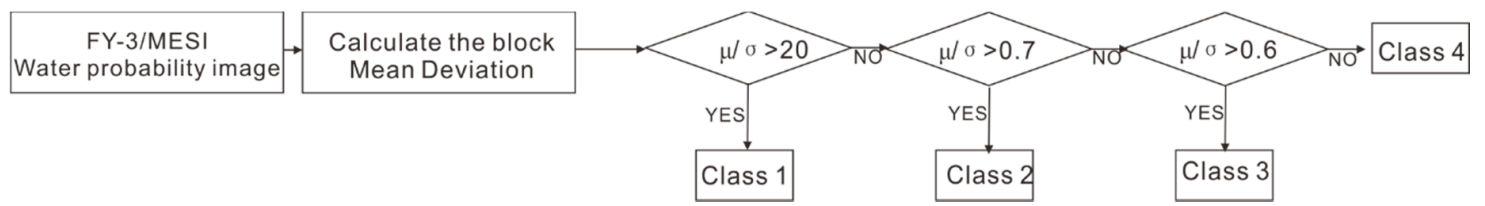

Figure 5. Rough classification flow chart of SMDPSO.

In the code for DPSO, the position vectors of all the particles form position matrix $\mathrm{X}$. The pixels in the block are divided into two categories: water and non-water. The velocity vectors of all particles form the velocity matrix $\mathrm{V}$. The particle objective function value is then calculated. The optimal particle history and global optimal solution are obtained, and the particle velocity and particle position are updated. Next, the fitness value of the particles is calculated, and the historical optimal and global optimal solutions of the particles are updated. After reaching the maximum iteration, the output global optimal solution is the final classification representation of the land surface water pixel and the non-land surface water pixel in the block.

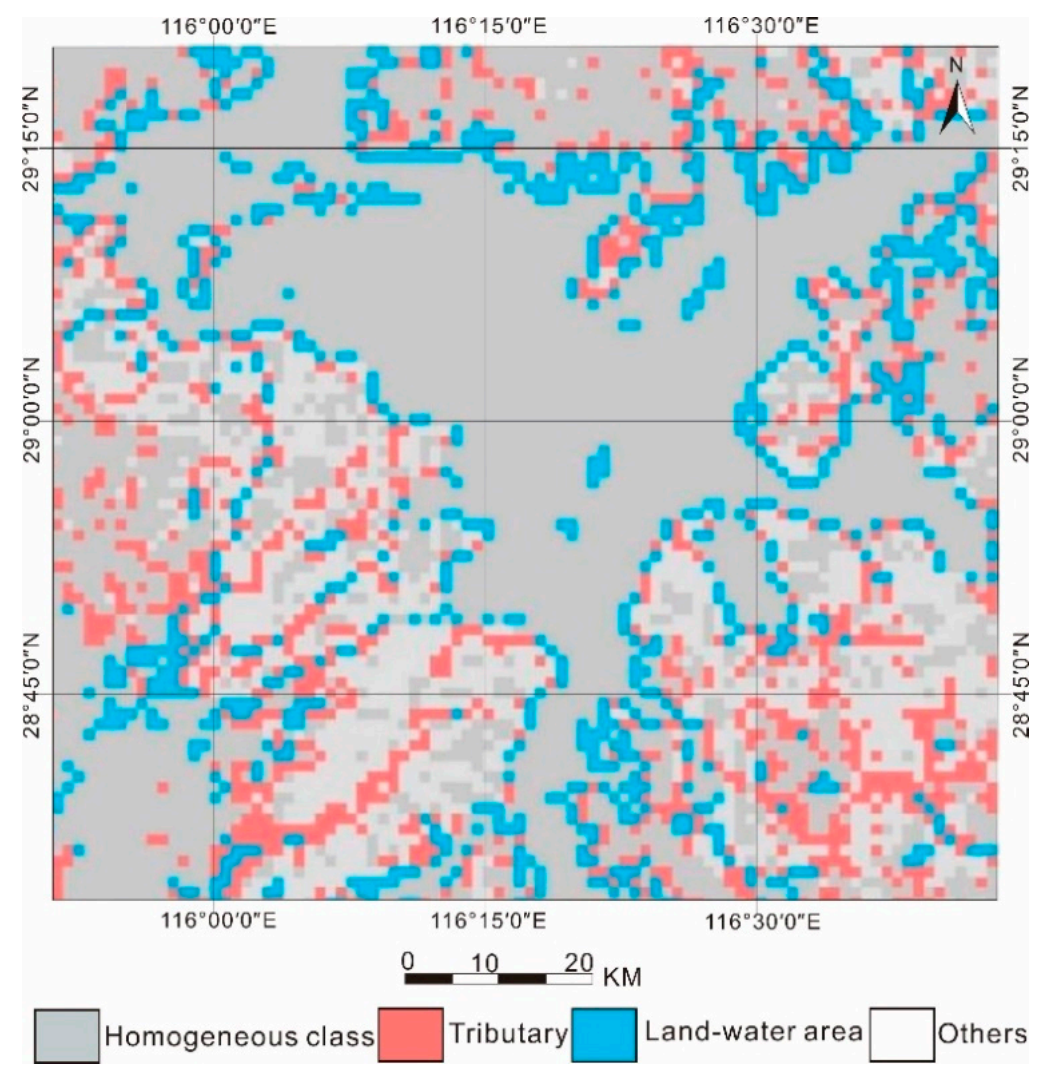

Figure 6. Rough classification result graph of SMDPSO.

\subsection{Extraction of Surface Water by SMDPSO+LFE Method}

For a particular image resolution, a river may appear to be about the width of a single-pixel or more, depending on the actual width of the river [39]. Figure 7 shows the feature differences between rivers with a single-pixel width and rivers with multiple pixels in the water probability image. In general, the techniques used to extract the feature width of a single pixel cannot be used directly to extract the same features at a higher resolution. A single-pixel width element is mapped by a single line in the generated vector database, while the multiple linear elements of pixel width must be represented as a set of polygons [40]. 


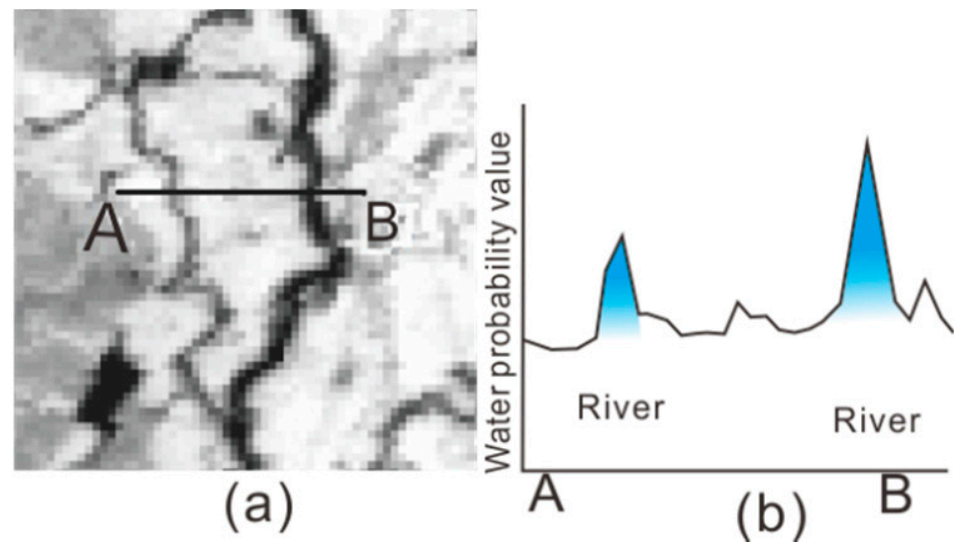

Figure 7. Probability map of the tributary water bodies: (a) water probability of tributaries; (b) probability curve of tributary water bodies.

SMDPSO+LFE method calculates the probability of the water body through the standard spectrum, and roughly classifies the image through the probability of the water body. The results of the rough classification are divided into two parts. As the flow chart is shown in Figure 8, the first part is used to extract water pixels via the DPSO algorithm for three categories. The second part is used to enhance the current characteristics of small tributaries and extract the small tributaries.

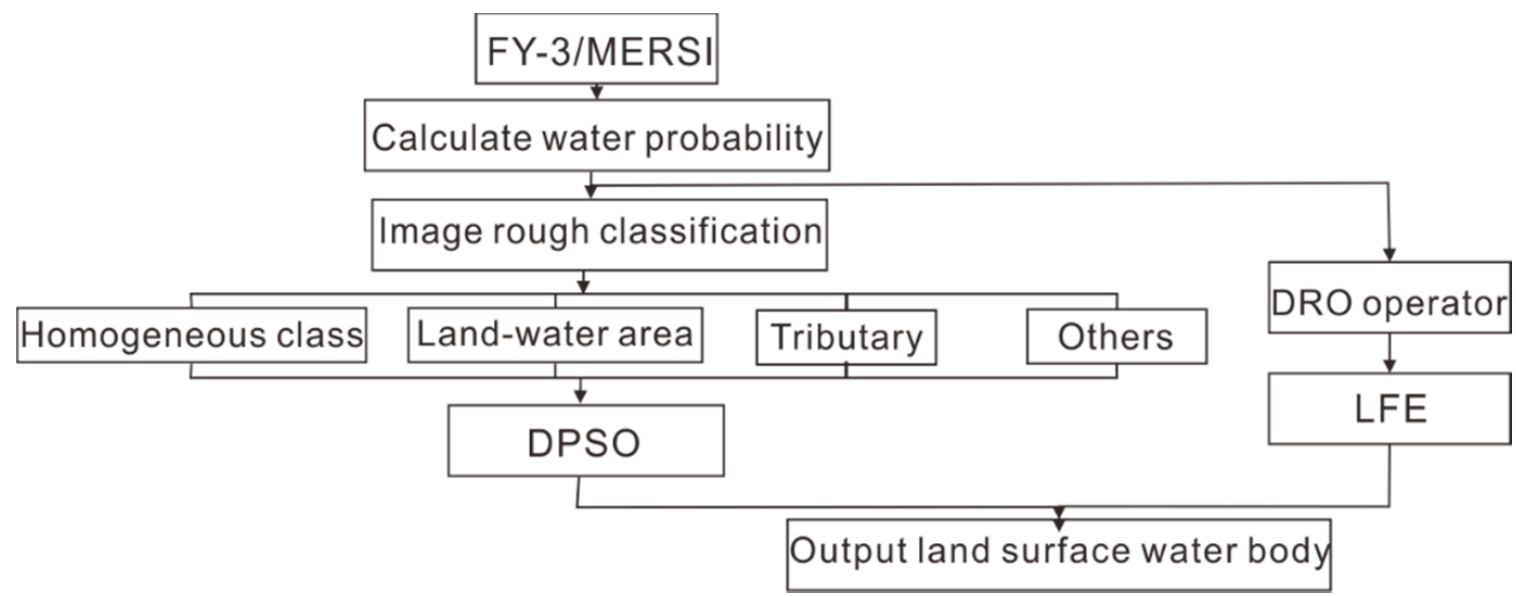

Figure 8. The flow chart of SMDPSO + linear feature enhancement (LFE).

The first stage involves extracting water pixels from three tributaries via the DPSO algorithm, and the second step is to enhance the current characteristics of small tributaries and extract the small tributaries [41,42]. The extraction of small tributaries from FY-3/MERSI images is mainly based on Fischler's work [43]. Fischler proposed a Duda Road Operator (DRO) in his study to identify rural roads from low-resolution remote sensing data by locating roads less than or equal to three pixels wide. The DRO was further studied and extended to extract natural features, such as coastlines and valleys. Fischler's research involves evaluating images pixel by pixel based on a set of operators, each of which measures the local image attributes through a pixel and returns a score indicating the likelihood that the pixel is a road [44-46]. The higher the calculated value of the operator, the more likely it is a road pixel.

In the FY-3/MERSI images, small tributaries showed as less than or equal to 3-pixel values, so the DRO operator was introduced to enhance the linear features and extract small tributaries. Rivers vary greatly in morphology due to their different points of origin. Rivers formed on mountains tend to be very tortuous in shape along with the direction of valleys. However, rivers in flat areas and artificially excavated rivers tend to be squarer in shape. Considering the effect of river shape on the enhancement of linear features, only the central pixel of the river and the pixels on both 
sides of the central pixel in different directions are considered in the process of introducing the DRO operator. Based on an image with an inconsistent width of river water pixels, $3 \times 3$ and $5 \times 5$ pixels were used to enhance the linear features of the image. Considering that the water probability value of the surface water pixel is larger than the rest of the pixel, to avoid the influence of other pixels, only the cases where the water probability value of the pixel in the center is larger than the two sides were calculated. The DRO operators include four operators in different directions to calculate the linear enhancement results for operators in different directions and determine the maximum values for $3 \times 3$ and $5 \times 5$ pixels in different directions as the final linear feature enhancement result values. The linear feature enhancement results according to the probabilistic image of the water body in the study area are shown in Figure 9.

Figure 9 shows that the small tributaries on the west bank of Poyang Lake are greatly enhanced and that the small tributaries have a high degree of integrity. For the wider parts of the river in the southwest bank, the width of the river pixel is greater than three, and the enhancement effect of the linear features of the DRO is not obvious. At the same time, the irregular edges of Poyang Lake were completely enhanced at the boundary of water and land. However, for the tributaries that are one-pixel wide, this linear enhancement is less effective due to the small differences between the water probability value of the tributaries and the surrounding pixels.

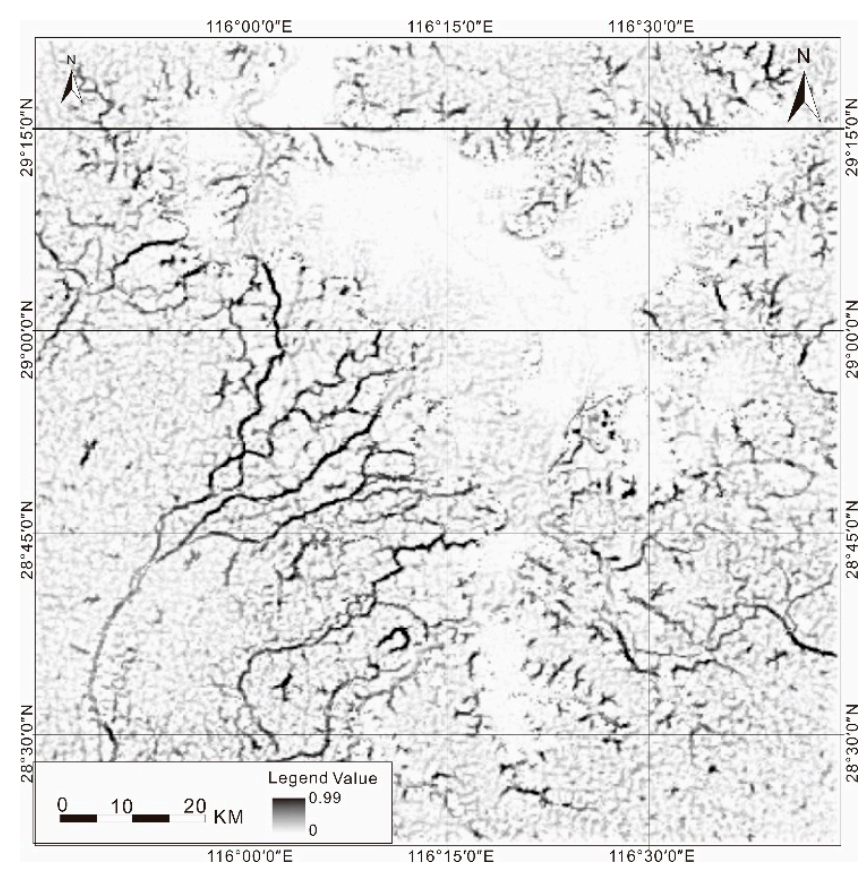

Figure 9. Linear feature enhancement result of the NDWI.

\subsection{Validation and Accuracy Evaluation Methods}

In this study, 7 methods were applied, including single-band threshold method, water body index method, knowledge decision tree classification method, supervised classification method, unsupervised classification method, SMDPSO, and SMDPSO+LFE.

A sensitivity analysis was carried out to evaluate the accuracy of the extraction of surface water using the standard water spectrum, block size, and iteration times. The standard water spectrum, block size, and iteration times are input parameters for the selected water extraction method. Three sampling areas were selected to evaluate the sensitivity of the selected water extraction method to the water standard water spectrum. These three sampling areas were identified as Lake Superior, the Congo river, and the Persian Gulf, and their maps are shown in Figure 10. 


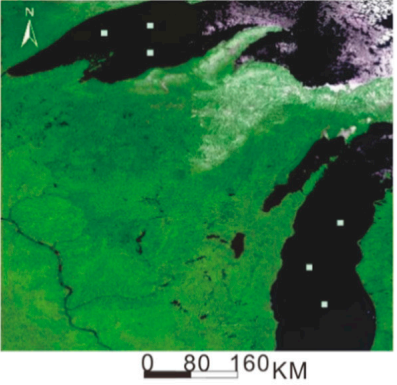

(a)

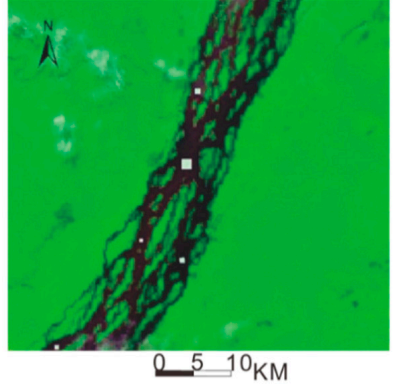

(b)

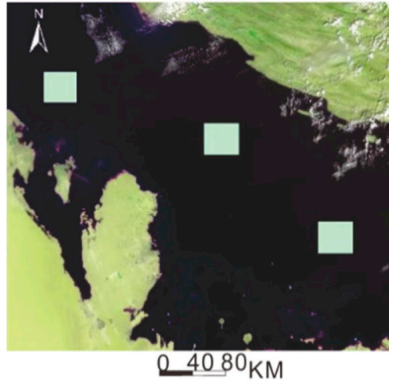

(c)

Figure 10. Three water spectral sampling image reference sample areas: (a) Lake Superior; (b) Congo river; (c) Persian Gulf.

For the block size, a larger size covers more adjacent pixels, but the calculation time and distance degree, which means the distance from the center of one block to the neighboring block's center point, of different block size algorithms are different. In this study, the block size of the research area of Poyang Lake varied from 3 to 10, the land surface water was extracted, and the corresponding OA was calculated according to the sampling results.

For the land surface water obtained by the iterations, the smaller the number of iterations is, the poorer the results are and the less likely they are to achieve the output of the objective function value. As the number of iterations grows larger, the results for the land surface water obtained by the iterations are improved, and the optimal solution becomes more likely to be achieved. However, the longer the number of iterations is, the longer it takes for the algorithm to output results. Different iterations were used to output the image water extraction results from the images in the research area and calculated the OA and Kappa coefficients from the water extraction results to find the most appropriate iteration times.

\section{Results}

\subsection{Extraction Results for Surface Water}

FY-3/MERSI image data of the Poyang Lake area on 2 September 2016, were used as the research image in this paper. The different methods described in Section 3 were used to extract the land surface water. The SVM in supervised classification method was applied to use Landsat data to obtain the water distribution results as a reference, because the SVM method is relatively stable for remote image classification and performs well in solving small sample volume data [47]. The resolution of the water extraction results is converted from 30 to $250 \mathrm{~m}$. The original FY-3/MERSI image and land surface water extraction results are shown in Figure 11.

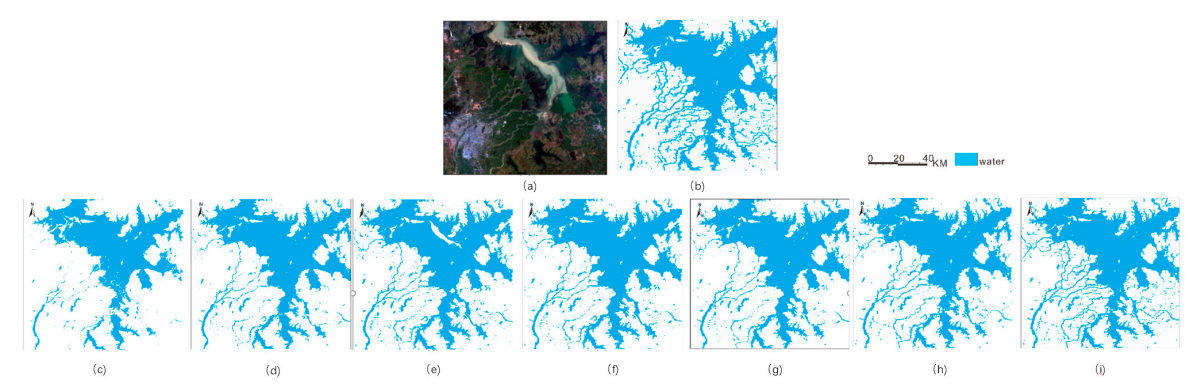

Figure 11. Remote sensing image and water extraction results of the different methods in research area 20160917: (a) FY-3/MERSI image; (b) Landsat data; (c) single-band threshold method; (d) water index method; (e) decision tree method; (f) supervised classification; (g) unsupervised classification; (h) SMDPSO; (i) SMDPSO+LFE. 
According to Figure 11, all the 7 methods can clearly show the large area of lakes. However, for rivers, especially relatively small tributaries, SMDPSO+LFE performed significantly better than the other six methods.

Figure 12 shows the detailed results of the partial image captured from the whole image. As the threshold value of the water index method was set too high, almost all the tributaries on the southwest shore of Poyang Lake were not extracted. Other methods can be used to extract the central pixel of the southwest shore-based river with a large width. However, for the river edge and tributaries with a width of fewer than two pixels, only the SMDPSO+LFE method is nearly perfect, and the extraction effect is better for small tributaries and discrete land surface waters.

In order to effectively use satellite data for flood monitoring during the flood season, we used the satellite data from July and August 2020 to extract the water body information of Poyang Lake area. As can be seen from the diagram, in the Poyang Lake region, since the beginning of this season in July, there was distribution of large water bodies, and in August, after the flood receded gradually, water area decreased significantly in the region. The water distribution maps are shown in the Figure 13.
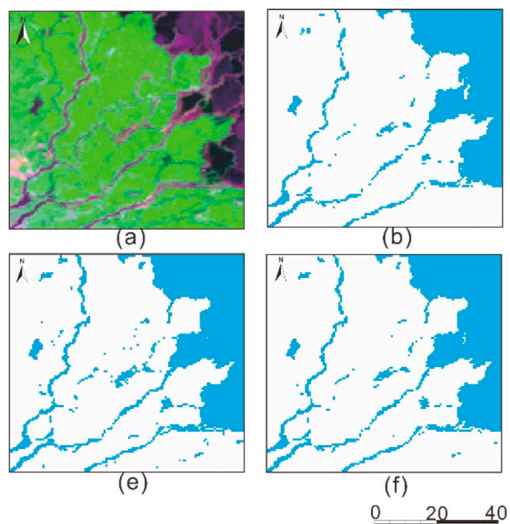
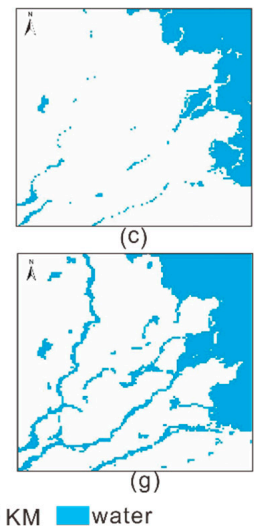
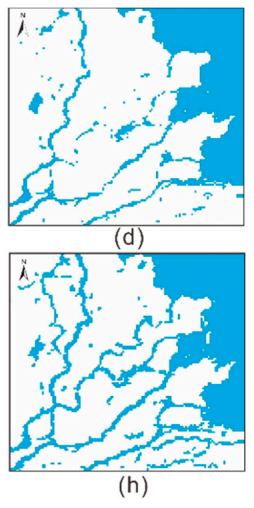

Figure 12. Extraction results of tributary water in the study area: (a) FY-3/MERSI image; (b) single-band threshold method; (c) water index method; (d) decision tree method; (e) supervised classification; (f) unsupervised classification; (g) SMDPSO; (h) SMDPSO+LFE.

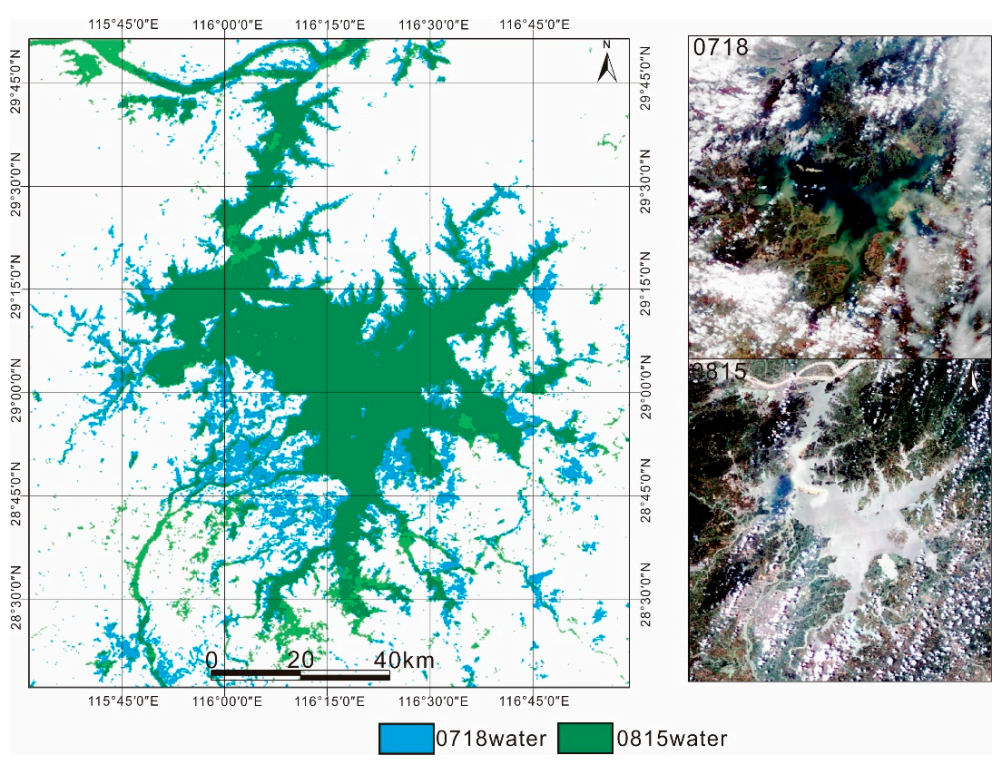

Figure 13. Water distribution in Poyang Lake region in July and August. 


\subsection{Verification of Accuracy}

Seven methods were used to evaluate the accuracy of the remote sensing image data of Poyang Lake, including the OA, Kappa coefficients, f1, and miou, as shown in Table 3.

Table 3. Comparison results of the coefficients of extraction using different methods.

\begin{tabular}{cccccccc}
\hline & Single-Band & Water Index & Decision Tree & $\begin{array}{c}\text { Supervised } \\
\text { Classification }\end{array}$ & $\begin{array}{c}\text { Unsupervised } \\
\text { Classification }\end{array}$ & SMDPSO & SMDPSO+LFE \\
\hline OA & $93.38 \%$ & $93.32 \%$ & $93.38 \%$ & $93.79 \%$ & $94.67 \%$ & $96.02 \%$ & $97.56 \%$ \\
\hline Kappa & 0.84 & 0.84 & 0.87 & 0.88 & 0.89 & 0.91 & 0.95 \\
\hline f1 & $90.77 \%$ & $90.56 \%$ & $92.43 \%$ & $91.87 \%$ & $95.24 \%$ & $96.54 \%$ & $96.99 \%$ \\
\hline miou & $86.65 \%$ & $86.46 \%$ & $87.96 \%$ & $87.20 \%$ & $89.75 \%$ & $92.19 \%$ & $95.17 \%$ \\
\hline
\end{tabular}

According to the above table, the OA and Kappa values of the SMDPSO+LFE classification results are the highest at $97.56 \%$ and 0.95 , respectively, while the OA and Kappa values of the water index method are the lowest at $92.32 \%$ and 0.8390 , respectively.

Comparing with the results of SMDPSO, the OA of SMDPSO+LFE increased to $97.56 \%$, the Kappa coefficient increased to 0.95 . This proves that linear enhancement is effective for improving the accuracy of water extraction. Therefore, SMDPSO+LFE is considered to be the most suitable method for the extraction of surface water in the Poyang Lake area.

\subsection{Stability and Sensitivity}

The land surface water extraction results of the eight test points based on SMDPSO+LFE are shown in Figure 14.

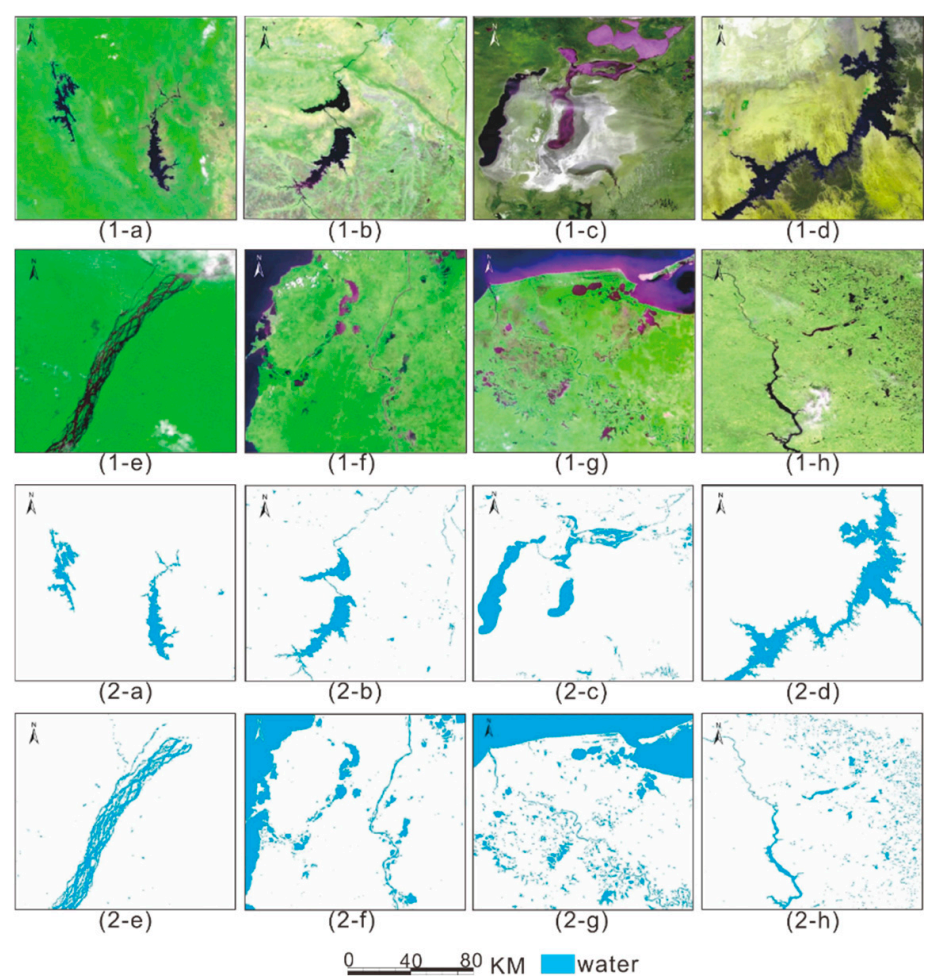

Figure 14. Global stability test sample: (a) Mountain lakes in Thailand; (b) Lake Gandhi in India; (c) Aral Sea in Kazakhstan; (d) Nasser reservoir in Egypt; (e) Congo river; (f) Magdalena river in Colombia; (g) Mexican coastal lake; (h) Mississippi River in the United States.

The OA and Kappa coefficients of the eight test areas are shown in Table 4. 
Table 4. The coefficient values of overall classification accuracy (OA) and Kappa in the eight test areas.

\begin{tabular}{ccccccccc}
\hline $\mathbf{c}$ & $\mathbf{A}$ & $\mathbf{B}$ & $\mathbf{C}$ & $\mathbf{D}$ & $\mathbf{E}$ & $\mathbf{F}$ & $\mathbf{G}$ & $\mathbf{H}$ \\
\hline OA & $97.11 \%$ & $97.84 \%$ & $94.66 \%$ & $99.23 \%$ & $96.78 \%$ & $94.86 \%$ & $94.79 \%$ & $95.15 \%$ \\
Kappa & 0.96 & 0.95 & 0.89 & 0.98 & 0.93 & 0.89 & 0.88 & 0.90 \\
\hline
\end{tabular}

Three sampling areas were selected to evaluate the sensitivity of SMDPSO+LFE to the standard water spectrum. The standard water spectrum vector values of the different areas applied to water probability are shown in Table 5 below.

Table 5. Comparison of the results for the coefficients of extraction using different methods.

\begin{tabular}{cccccc}
\hline & Blue & Green & Red & Nir & NDVI \\
\hline Lake Superior & 0.0745 & 0.0403 & 0.0240 & 0.0173 & 0.8521 \\
Congo river & 0.1167 & 0.0837 & 0.6320 & 0.5500 & 0.6294 \\
Persian Gulf & 0.1058 & 0.0858 & 0.6230 & 0.5090 & 0.7098 \\
\hline
\end{tabular}

The overall classification accuracy of SMDPSO+LFE using different standard water spectral values is shown in Figure 15. Lake Superior has a relatively high OA value in the study area and the eight stability test areas.

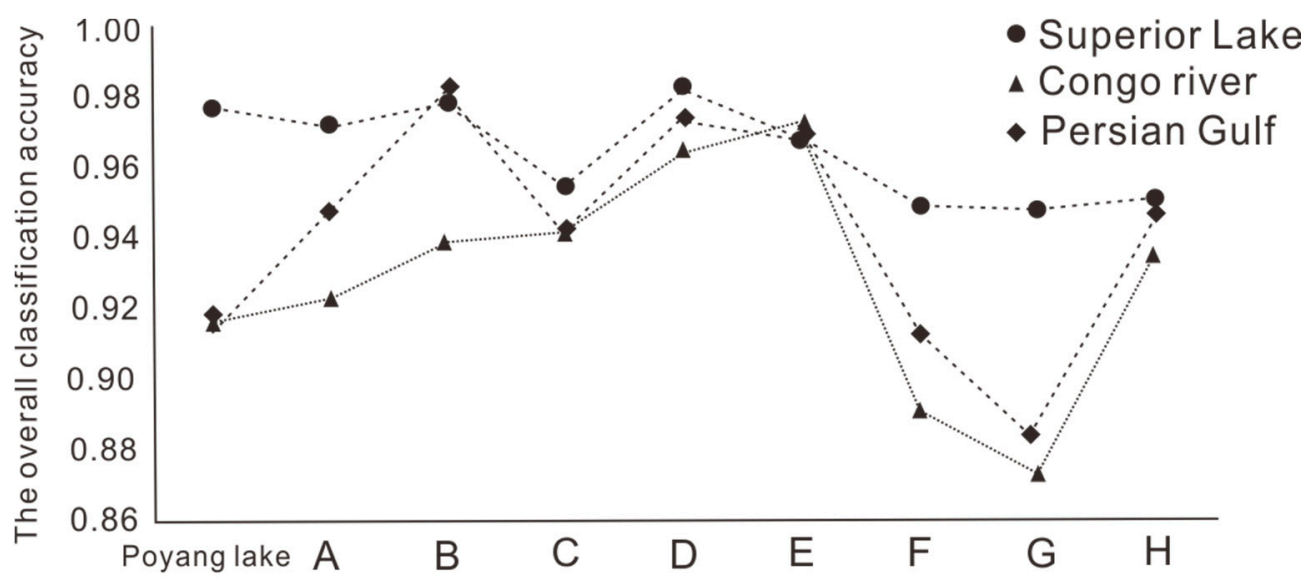

Figure 15. The overall classification accuracy of the water spectrum based on different standards.

In this study, the size of the block in the study area of Poyang Lake changed from 3 to 10 were used to extract surface water separately, and the corresponding OA was calculated according to the sampling results, as shown in Table 6.

Table 6. Overall classification accuracy of different block sizes.

\begin{tabular}{ccccccccc}
\hline Block Size & $\mathbf{3}$ & $\mathbf{4}$ & $\mathbf{5}$ & $\mathbf{6}$ & $\mathbf{7}$ & $\mathbf{8}$ & $\mathbf{9}$ & $\mathbf{1 0}$ \\
\hline OA & $97.33 \%$ & $97.64 \%$ & $97.66 \%$ & $97.39 \%$ & $96.94 \%$ & $95.59 \%$ & $93.61 \%$ & $93.00 \%$ \\
\hline
\end{tabular}

In this paper, different iterations were used to output the image water extraction results from the images in the research area, the OA and Kappa coefficients were calculated for the water extraction results.

The number of iterations and the relationship between the OA and Kappa coefficients are shown in Figure 16. 


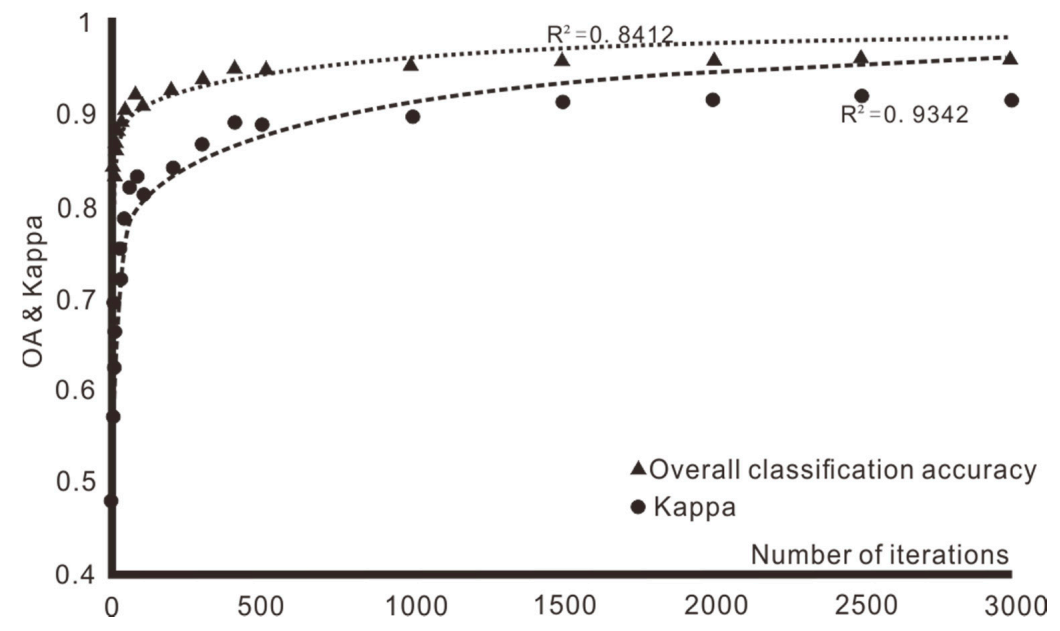

Figure 16. The number of iterations and the relationship between the OA and Kappa coefficients.

\section{Discussion}

The single-band threshold method is a good method to distinguish surface water from land. Through manual visual interpretation, this method could roughly extract the surface water in the study area. However, most of the small tributaries and discrete surface waters on the southwest and southeast shores of the Poyang Lake area were not successfully separated; only some of the rougher rivers were extracted. Thus, there are still some imperfections at the extraction of river's edge.

The water index extraction method can be used to extract the basic shape of the main body of Poyang Lake. However, the NDWI is sensitive to sediment, and the area of Poyang Lake and a large number of rivers are mixed with a great deal of sediment. Moreover, the water index method only extracts wider rivers.

The decision tree classification method can extract the general water bodies and rivers of Poyang Lake. However, lakes with a large amount of suspended sediment and mixed water cannot be distinguished by decision tree classification. The high concentration suspended sediment water body was incorrectly classified as a non-water body. Moreover, this method could not distinguish the shallow bank at the edge of the lake or extract the small tributary water body. At the same time, the knowledge-based decision tree method requires that researchers have a good understanding of the image features in the early stage when constructing the decision tree. The precision of the classification results of the decision tree was determined by sample selection. Images in different regions are needed to build special decision trees, so their utility is low.

There were many misclassifications in the supervised classifications for the shadowed part of the western mountains. At the same time, the surface water extraction results were also not perfect for the area of the lake edge with a complex shape. In addition, supervisory classification methods require prior field investigations or prior knowledge and are complex to operate.

The unsupervised classification results were not accurately extracted from the shoals on the lake boundary. At the same time, for the junction between the river and the building, part of the building was divided into land surface waters. The unsupervised classification does not need to be supervised during the selection and implementation of classifiers. However, after the implementation of classifiers, it is necessary to judge the results according to the classification characteristics and then merge the classifications, which requires accurate discrimination.

The SMDPO extracted not only the basic surface water of Poyang Lake but also some relatively small tributaries. The general directions of the rivers were also clearly indicated, and some discrete lakes were successfully distinguished. However, the land surface water in the building area was relatively confused. The results of SMDPSO are better than those of the 5 previous methods.

On the basis of SMDPSO, the SMDPO+LFE method extracted some relatively small tributary waters. In addition, some small tributaries and lake water that take up only one pixel were extracted. 
According to the stability study of SMDPSO+LFE, the spectral reflectance of vegetation, cloud, and ice is quite different from the spectral value of standard water, so the water probability value is relatively low. This method can accurately distinguish vegetation, clouds, and ice, as well as thin clouds. The SMDPSO+LFE method was used to extract the images of the Poyang Lake research area, the Magdalena River in Colombia, and the coastal lake in Mexico. This method was shown to be highly sensitive to shoal and silt, as it could correctly distinguish between shoal, silt, and surface water. At the same time, this method offers good feedback for small tributaries and lakes with a pixel width of less than two and can effectively extract small tributaries, small lakes, and small puddles. However, the continuity of small tributaries needs to be improved.

Mountain lakes in Thailand, Gandhi lake in India, Nasser reservoir in Egypt, and Congo river in the Congo are characterized by obvious surface waters due to their simple image types.

The OA and Kappa coefficient values of the classification results of surface waters in these areas were both high, with an overall classification accuracy higher than $96.5 \%$ and Kappa coefficient values higher than 0.93 .

In Kazakhstan's Aral sea, Colombia's Magdalena river, Mexico's beach lakes, and in the Mississippi River, due to the complexity of ground type, shallow water and silt, sea tide, and cloud shadow, epicontinental water mixed with the rest of the class information; water extraction result complete degree is not high; $\mathrm{OA}$ is relatively low, at around $95 \%$, and the Kappa coefficient is about 0.89 .

In terms of sensitivity, the sizes of the blocks increased from 3 to 5 , and the overall classification accuracy gradually increased. With the increase in the block size, the greater distance limit of the block is solved, and the overall classification accuracy gradually decreases. Considering the solution time for land surface water, when the size of the block is 4 , there are $65,536\left(2^{16}\right)$ possible solutions for land surface water in any block. When the block size is 5 , there are $33,554,432\left(2^{25}\right)$ kinds of surface water in any block. The number of iterations is multiplied. Therefore, to achieve the highest accuracy and meet the low time requirements, the optimal block size chosen in this paper is 4 .

Through an approximate curve analysis of the OA and Kappa coefficients and the number of iterations in SMDPSO, the correlation between the fitting relationships of the OA and the Kappa coefficients and the number of iterations and the logarithm function was higher than 0.84 . With a gradual increase in the number of iterations, the distribution law of logarithmic growth was realized. With 0-1000 iterations, the overall classification accuracy and Kappa coefficient increased rapidly. The growth slowed in 1000-2000 iterations, and the overall classification accuracy and Kappa coefficient tended to be stable after 2000 iterations. Since a higher number of iterations means a longer surface water extraction time, the number of iterations for all images in this paper was set at 2500 .

This research focuses on the comparison of water extraction methods. Five traditional methods are already mature. On the basis of comparing these methods, this paper added SMDPSO and SMDPSO+LFE to conduct experiments on water extraction methods. In the experiment of this method, SMDPSO+LFE is considered to have better accuracy, stability, and sensitivity.

The results show that the accuracies of the seven methods are all greater than $93 \%$. However, from the perspective of overall accuracy, SMDPSO+LFE is $3 \%$ to $4 \%$ higher than the conventional 5 methods. Kappa coefficient is 0.11 to 0.06 higher. In water extraction, including many other classification models, the process of improving the accuracy is relatively slow, which mainly depends on the characteristics of the data. Even a small increase in accuracy is of great significance, especially in the extraction of river tributaries.

\section{Conclusions}

Based on FY-3 remote sensing satellite data, seven methods were applied to extract the surface water of the Poyang Lake, China. A confusion matrix analysis on the verification samples selected by Landsat 8 OLI was conducted to compare with the seven classification methods. Compared with other methods, SMDPO+LFE is considered to be the best method for extracting the water of Poyang Lake 
because of its high accuracy on water extraction, especially on small tributary waters. It also shows good performance in terms of sensitivity and durability.

Among the surface water extraction methods in the Poyang Lake region, the classification accuracy and Kappa coefficient of the seven methods were all higher than $93 \%$ and 0.84 respectively. SMDPSO+LFE classification accuracy reached $97.56 \%$ and Kappa coefficient reached 0.95 . These results show that the SMDPSO+LFE method represents the highest accuracy among the seven methods in this case study. The algorithms of SMDPSO+ LFE determined three parameters of standard water spectrum, block size, and iteration times in the early stage of the surface water body extraction model and have a good extraction effect.

In terms of the adaptability of different regions, eight qualitative regions of different terrestrial surface water types, landscapes, and topographic features are selected globally. SMDPSO+LFE algorithm was used to extract surface water from FY-3 images of eight regions. The results show that water extraction is effective and can be divided into ice, shoal, silt, and small tributaries. Sensitivity analysis was carried out through the standard water spectrum, block size, and iteration times. The results show that the selection of Lake Superior as the standard water spectrum, block size of 4 , and iteration times of 2500 have high classification accuracy and Kappa coefficient. The algorithm is also more efficient.

However, compared with other methods, the SMDPSO+LFE method is slightly more complicated in the implementation process. Other conventional methods can be completed with many software. SMDPSO+LFE does not support by any software by now, which means it needs to be programmed. In a follow-up study, intelligent optimization algorithms will be introduced. The surface water body extraction stability of SMDPSO+LFE method under different programming languages will also be explored.

Author Contributions: X.W., W.X., and W.H. conceived and designed the experiments; X.W., W.X., and K.B. performed the experiments; J.S. and Z.M. contributed to the data and material collection; X.W., W.X., W.H., K.B., J.S., and H.L. analyzed the data and wrote the paper. All authors have read and agreed to the published version of the manuscript.

Funding: This research was funded by the Science and Technology Program of Hebei, grant number 19255901D, and the National Defense Science and Technology Key Laboratory of Remote Sensing Information and Image Analysis Technology of China, grant number 6142A010301.

Conflicts of Interest: The authors declare no conflict of interest.

\section{References}

1. Shen, L.; Li, C. Water body extraction from Landsat ETM+ imagery using adaboost algorithm. In Proceedings of the 2010 18th International Conference on Geoinformatics, Beijing, China, 18-20 June 2010; pp. 1-4.

2. Frazier, P.S.; Page, K.J. Water body detection and delineation with Landsat TM data. Photogramm. Eng. Remote Sens. 2000, 66, 1461-1468.

3. Braud, D.; Feng, W. Semi-Automated Construction of the Louisiana Coastline Digital Land/Water Boundary Using Landsat Thematic Mapper Satellite Imagery. In Louisiana Applied Oil Spill Research and Development Program; OS2 RAPD Technical Report Series; Louisiana State University: Baton Rouge, LA, USA, 1998; Volume 97.

4. Wang, H.; Qin, F. Summary of the research on water body extraction and application from remote sensing image. Sci. Surv. Mapp. 2018, 43, 23-32.

5. Ouma, Y.O.; Tateishi, R. A water index for rapid mapping of shoreline changes of five East African Rift Valley lakes: An empirical analysis using Landsat TM and ETM+ data. Int. J. Remote Sens. 2006, 27, 3153-3181. [CrossRef]

6. Jiang, W.; He, G.; Long, T.; Ni, Y.; Liu, H.; Peng, Y.; Lv, K.; Wang, G. Multilayer Perceptron Neural Network for Surface Water Extraction in Landsat 8 OLI Satellite Images. Remote Sens. 2018, 10, 755. [CrossRef]

7. Hong, Z.; Li, X.; Han, Y.; Zhang, Y.; Wang, J.; Zhou, R.; Hu, K. Automatic sub-pixel coastline extraction based on spectral mixture analysis using EO-1 Hyperion data. Front. Earth Sci. 2019, 13, 478-494. [CrossRef] 
8. Yang, J.; Du, X. An enhanced water index in extracting water bodies from Landsat TM imagery. Ann. GIS 2017, 23, 1-8. [CrossRef]

9. Jiang, W.; Ni, Y.; Pang, Z.; He, G.; Fu, J.; Lu, J.; Yang, K.; Long, T.; Lei, T. A new index for identifying water body from sentinel-2 satellite remote sensing imagery. ISPRS Ann. Photogramm. Remote Sens. Spat. Inf. Sci. 2020, 3, 33-38. [CrossRef]

10. Jupp, D.L.B.; Mayo, K.K.; Kucher, D.A.; Heggen, S.J.; Kendall, S.W.; Radke, B.M.; Ayling, T. Landsat based interpretation of the Cairns section of the Great Barrier Reef Marine Park; Canberra, ACT, CSIRO Division of Water \& Land Resources: Canberra, Australia, 1985.

11. Nguyen, D. Water body extraction from multi spectral image by spectral pattern analysis. ISPAr 2012, 39, 181-186. [CrossRef]

12. Møller-Jensen, L. Knowledge-based classification of an urban area using texture and context information in Landsat-TM imagery. Photogramm. Eng. Remote Sens. 1990, 56, 899-904.

13. Townshend, J.R.G.; Justice, C. Analysis of the dynamics of African vegetation using the normalized difference vegetation index. Int. J. Remote Sens. 1986, 7, 1435-1445. [CrossRef]

14. McFeeters, S.K. The use of the Normalized Difference Water Index (NDWI) in the delineation of open water features. Int. J. Remote Sens. 1996, 17, 1425-1432. [CrossRef]

15. Han-Qiu, X. A study on information extraction of water body with the modified normalized difference water index (MNDWI). J. Remote Sens. 2005, 5, 589-595.

16. Eberhart, R.; Kennedy, J. Particle swarm optimization. In Proceedings of the IEEE International Conference on Neural Networks, Perth, WA, USA, 27 November-1 December 1995.

17. Poli, R.; Kennedy, J.; Blackwell, T. Particle swarm optimization. Swarm Intell. 2007, 1, 33-57. [CrossRef]

18. Garcia-Nieto, J.; Olivera, A.C.; Alba, E. Optimal Cycle Program of Traffic Lights With Particle Swarm Optimization. IEEE Trans. Evol. Comput. 2013, 17, 823-839. [CrossRef]

19. Lin, L.; Lin, W.-Q.; Jiang, J.-H.; Shen, G.-L.; Yu, R.-Q. QSAR analysis of substituted bis[(acridine-4-carboxamide)propyl]methylamines using optimized block-wise variable combination by particle swarm optimization for partial least squares modeling. Eur. J. Pharm. Sci. 2005, 25, 245-254. [CrossRef]

20. Jia, K.; Jiang, W.; Li, J.; Tang, Z. Spectral matching based on discrete particle swarm optimization: A new method for terrestrial water body extraction using multi-temporal Landsat 8 images. Remote Sens. Environ. 2018, 209, 1-18. [CrossRef]

21. Yu, W. Flood Disaster Remote Sensing Monitoring System Based on FY-3A/MERSI Image; University of Electronic Science and Technology of China: Chengdu, China, 2013.

22. Qian, M.; Lasheng, Z. Characteristics of low-water level changes in Lake Poyang during 1952-2011. J. Lake Sci. 2012, 24, 675-678. [CrossRef]

23. Peng, W.; Geying, L.; Xiaolan, H. Simulation of the impact of Lake Poyang Project on the dynamic of lake water level. J. Lake Sci. 2014, 26, 29-36. [CrossRef]

24. Huang, J.; Gomez-Dans, J.; Huang, H.; Ma, H.; Wu, Q.; Lewis, P.; Liang, S.; Chen, Z.; Xue, J.-H.; $\mathrm{Wu}, \mathrm{Y}$; et al. Assimilation of remote sensing into crop growth models: Current status and perspectives. Agric. For. Meteorol. 2019, 276, 107609. [CrossRef]

25. Zhuo, W.; Huang, J.; Li, L.; Zhang, X.; Ma, H.; Gao, X.; Huang, H.; Xu, B.; Xiao, X. Assimilating Soil Moisture Retrieved from Sentinel-1 and Sentinel-2 Data into WOFOST Model to Improve Winter Wheat Yield Estimation. Remote Sens. 2019, 11, 1618. [CrossRef]

26. Huang, J.; Zhuo, W.; Li, Y.; Huang, R.; Sedano, F.; Su, W.; Dong, J.; Tian, L.; Huang, Y.; Zhu, D.; et al. Comparison of three remotely sensed drought indices for assessing the impact of drought on winter wheat yield. Int. J. Digit. Earth 2018, 13, 504-526. [CrossRef]

27. Huang, R.; Huang, J.-X.; Zhang, C.; Ma, H.-Y.; Zhuo, W.; Chen, Y.-Y.; Zhu, D.-H.; Wu, Q.; Mansaray, L.R. Soil temperature estimation at different depths, using remotely-sensed data. J. Integr. Agric. 2020, 19, 277-290. [CrossRef]

28. Feyisa, G.L.; Meilby, H.; Fensholt, R.; Proud, S.R. Automated Water Extraction Index: A new technique for surface water mapping using Landsat imagery. Remote Sens. Environ. 2014, 140, 23-35. [CrossRef]

29. Parkinson, C.L.; Ward, A.; King, M.D. Earth Science Reference Handbook: A Guide to NASA's Earth Science Program and Earth Observing Satellite Missions; National Aeronautics and Space Administration: Washington, DC, USA, 2006; p. 277. 
30. Jinlong, F.; Yeping, Z.; Changbao, L.; Wenbo, X.; Shaojie, L.; Fei, X.; Zhihao, Q. Systematic Analysis of Geometric Performance of Fengyun-3C MERSI Satellite Data Using Image Chip Matching Method. Remote Sens. Technol. Appl. 2018, 33, 621-627.

31. Ji, L.; Zhang, L.; Wylie, B. Analysis of Dynamic Thresholds for the Normalized Difference Water Index. Photogramm. Eng. Remote Sens. 2009, 75, 1307-1317. [CrossRef]

32. Cao, R.; Li, C.J.; Liu, L.Y.; Wang, J.H.; Yan, G.J. Extracting Miyun reservoirs water area and monitoring its change based on a revised normalized different water index. Sci. Surv. Mapp. 2008, 33, 158-160.

33. Soti, V.; Tran, A.; Bailly, J.-S.; Puech, C.; Seen, D.L.; Bégué, A. Assessing optical earth observation systems for mapping and monitoring temporary ponds in arid areas. Int. J. Appl. Earth Obs. Geoinf. 2009, 11, 344-351. [CrossRef]

34. Jian, X.; Zhang, Z.G.; Qiu, Y.G.; Zhang, W. Research Progress in Water Extraction Based on Remote Sensing Data of MODIS. J. Langfang Teach. Coll. 2014.

35. Kaplan, G.; Avdan, U. Object-based water body extraction model using Sentinel-2 satellite imagery. Eur. J. Remote Sens. 2017, 50, 137-143. [CrossRef]

36. Yang, Y.; Liu, Y.; Zhou, M.; Zhang, S.; Zhan, W.; Sun, C.; Duan, Y. Landsat 8 OLI image based terrestrial water extraction from heterogeneous backgrounds using a reflectance homogenization approach. Remote Sens. Environ. 2015, 171, 14-32. [CrossRef]

37. Pekel, J.-F.; Cottam, A.; Gorelick, N.; Belward, A.S. High-resolution mapping of global surface water and its long-term changes. Nature 2016, 540, 418-422. [CrossRef] [PubMed]

38. De Azevedo, F.M.T.; Vale, Z.; Oliveira, P.B.D.M. A Decision-Support System Based on Particle Swarm Optimization for Multiperiod Hedging in Electricity Markets. IEEE Trans. Power Syst. 2007, 22, 995-1003. [CrossRef]

39. McKeown, D.M.; Denlinger, J.L. Cooperative methods for road tracking in aerial imagery. In Proceedings of the CVPR'88: The Computer Society Conference on Computer Vision and Pattern Recognition, Ann Arbor, MI, USA, 5-9 June 1988.

40. Zlotnick, A.; Carnine, P. Finding road seeds in aerial images. CVGIP Image Underst. 1993, 57, 243-260. [CrossRef]

41. Wang, J.; Howarth, P. Edge Following As Graph Searching And Hough Transform Algorithms For Linement Detection. In Proceedings of the 12th Canadian Symposium on Remote Sensing Geoscience and Remote Sensing Symposium, Vancouver, BC, Canada, 10-14 July 1989; Volume 1, pp. 93-96. [CrossRef]

42. Dobie, M.R.; Lewis, P.H. Extracting curvilinear features from remotely sensed images using minimum cost path techniques. In Proceedings of the 1st International Conference on Image Processing, Austin, TX, USA, 13-16 November 1994.

43. Fischler, M.; Tenenbaum, J.; Wolf, H. Detection of Roads and Linear Structures in Low-Resolution Aerial Imagery Using a Multisource Knowledge Integration Technique. In Readings in Computer Vision; Elsevier BV: Amsterdam, The Netherlands, 1987; pp. 741-752.

44. Geman, D.; Jedynak, B. An active testing model for tracking roads in satellite images. IEEE Trans. Pattern Anal. Mach. Intell. 1996, 18, 1-14. [CrossRef]

45. Barzohar, M.; Cohen, M.; Ziskind, I.; Cooper, D.B. Fast Robust Tracking of Curvy Partially Occluded Roads in Clutter in Aerial Images. In Automatic Extraction of Man-Made Objects from Aerial and Space Images (II); Springer: Berlin, Germany, 1997; pp. 277-286.

46. Nagao, M.; Matsuyama, T.; Mori, H. Structural analysis of complex aerial photographs. In Proceedings of the 6th International Joint Conference on Artificial Intelligence, Tokyo, Japan, 20 August 1979; Volume 2.

47. Ge, Q.Z.; Ling, Z.C.; Qiong, L.; Hui, X.X.; Zhang, G. High efficient classification on remote sensing images based on SVM. Int. Arch. Photogramm. Remote Sens. Spat. Inf. Sci. 2008, 37, 1011-1014.

Publisher's Note: MDPI stays neutral with regard to jurisdictional claims in published maps and institutional affiliations.

(C) 2020 by the authors. Licensee MDPI, Basel, Switzerland. This article is an open access article distributed under the terms and conditions of the Creative Commons Attribution (CC BY) license (http://creativecommons.org/licenses/by/4.0/). 